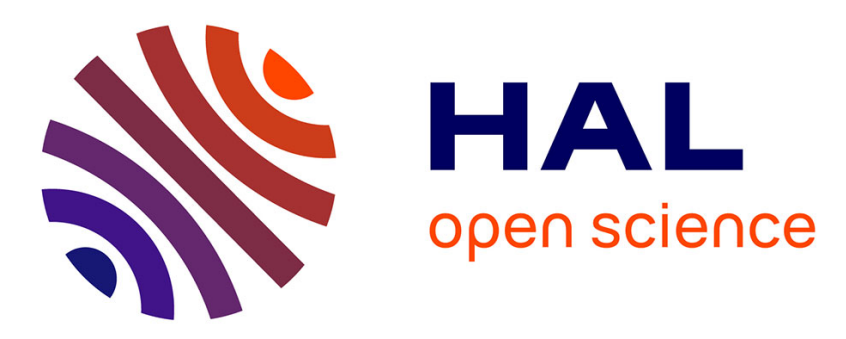

\title{
5. Étude par effet tunnel de jonctions métal-semiconducteur en présence d'une pression hydrostatique
}

\author{
P. Guétin, G. Schreder
}

\section{To cite this version:}

P. Guétin, G. Schreder. 5. Étude par effet tunnel de jonctions métal-semiconducteur en présence d'une pression hydrostatique. Revue de Physique Appliquée, 1970, 5 (6), pp.901-901. 10.1051/rphysap:0197000506090102 . jpa-00243475

HAL Id: jpa-00243475

https://hal.science/jpa-00243475

Submitted on 1 Jan 1970

HAL is a multi-disciplinary open access archive for the deposit and dissemination of scientific research documents, whether they are published or not. The documents may come from teaching and research institutions in France or abroad, or from public or private research centers.
L'archive ouverte pluridisciplinaire HAL, est destinée au dépôt et à la diffusion de documents scientifiques de niveau recherche, publiés ou non, émanant des établissements d'enseignement et de recherche français ou étrangers, des laboratoires publics ou privés. 


\title{
5. ÉTUDE PAR EFFET TUNNEL DE JONCTIONS MÉTAL-SEMICONDUCTEUR EN PRÉSENCE D'UNE PRESSION HYDROSTATIQUE
}

\author{
P. GUÉTIN et G. SCHREDER
}

Laboratoire d'Electronique et Physique Appliquée, 94, Limeil-Brevannes, France

Les jonctions métal-semiconducteur ont été soumises à des pressions hydrostatiques variant de 0 à 15 kbars. Les résultats sont donnés pour l'accroissement de la hauteur de la barrière dans un système $\mathrm{Au} / n \mathrm{GaAs}$ à la température ambiante. L'effet tunnel à $4.2^{\circ} \mathrm{K}$ dans des jonctions $\mathrm{Pb} / n \mathrm{GaAs}$ est décrit et nous montrons les variations caractéristiques des dérivées première et seconde de $I(V)$ : par exemple les modifications $\mathrm{du}$ fond continu en conductance, le décalage des phonons longitudinaux optiques, la variation de la densité d'états du supraconducteur. Nous discutons les possibilités de détermination en énergie des paramètres des minima secondaires dans la bande de conduction de GaAs. 